\title{
The Market Structure for Internet Search Engines
}

\author{
RAHUL TELANG, UDAY RAJAN, AND \\ TRIDAS MUKHOPADHYAY
}

RAHUl Telang is an Assistant Professor of Information Systems at H. John Heinz III School of Public Policy and Management, at Carnegie Mellon University. He received his Ph.D. in Information Systems from GSIA, Carnegie Mellon University in 2002. His research interests include consumers' use of new technologies like search engines and peer-to-peer networks, and empirical and analytical models of software security and vulnerabilities. His current work on e-business examines loyalty on the Internet, competition and impact of used-goods markets on retailers and suppliers. His recent papers have studied the impact of patching on software quality, markets for software vulnerabilities, and so on. His research has appeared in Journal of Marketing Research, Journal of Information Theory and Application, among others journals.

UDAY RAJAN is an Associate Professor of Finance at the University of Michigan Business School. He received his Ph.D. in Economics from Stanford University in 1995. His primary areas of interests are game theory and applied game theory. He is broadly interested in strategic interaction and market structures in different contexts. Current IS-related research projects include competition among Internet search engines, the effects of personalized pricing, and internet referral services. His research has appeared in journals such as American Economic Review, Journal of Economic Theory, and Journal of Finance.

TRIDAS MUKHOPADHYAY is the Deloitte Consulting Professor of e-Business at Carnegie Mellon University. His research interests include strategic use of IT, business-to-business commerce, business value of information technology, economics of cyber security, and software development productivity. His research appears in Information Systems Research, Journal of Management Information Systems, Communications of the ACM, Journal of Manufacturing and Operations Management, MIS Quarterly, Omega, IEEE Transactions on Software Engineering, Journal of Operations Management, Accounting Review, Management Science, Decision Support Systems, Journal of Experimental and Theoretical Artificial Intelligence, Journal of Organizational Computing, International Journal of Electronic Commerce, American Psychologist, and other publications. He has been on the Editorial Boards of Information Systems Frontier, Journal of Management Information Systems, Journal of Organizational Computing and Electronic Commerce, Management Information Systems Quarterly, Journal of the Association for Information Systems, International Journal of Electronic Commerce, and Management Science and Information Systems Research.

ABSTRACT: The Internet search engine market has seen a proliferation of entrants over the past few years. Whereas Yahoo was the early market leader, there has been

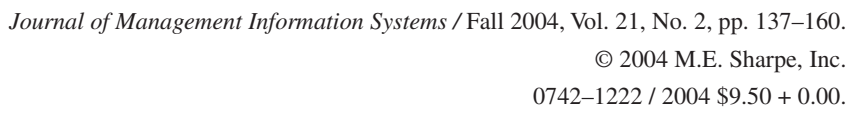


entry by both lower-quality engines and higher-quality ones (such as Google). Prior work on quality differentiation requires that low-quality products have low prices in order to survive in a market with high-quality products. However, the price charged to users of search engines is typically zero. Therefore, consumers do not face a tradeoff between quality and price. Why do lower-quality products survive in such a market? We develop a vertical differentiation model that explains this phenomenon. The quality of the results provided by a search engine is inherently stochastic, and there is no charge for using an engine. Therefore, users who try out one engine may consult a lower-quality engine in the same session. This "residual demand" allows lower-quality products to survive in equilibrium. We then extend our model to incorporate horizontal differentiation as well and show that residual demand leads to higher quality and less differentiation in this market. Engines want to attract competitors' customers and therefore have a strong incentive to be "similar" to each other.

KEY WORDS AND PHRASES: e-commerce, market structure, product differentiation, residual demand, search engines.

THE MARKET FOR INTERNET SEARCH ENGINES has witnessed rapid growth since its inception. Search engines and search engine-based portals consistently rank as some of the heavily visited sites in the market. ${ }^{1}$ On the consumer side, surveys indicate that search engines are the most important promotional method used by e-commerce sites and they represent the most common way the new sites are discovered by users. Users spend a significant amount of time on search engines looking for relevant information [8].

This market has also seen many changes on the side of the firms. Yahoo was an early entrant and market leader. Subsequently, the market has witnessed the entry of different engines with both lower-quality engines and higher-quality ones (such as Google, now the preeminent engine). Hundreds of engines are in the market, despite the presence of a few well-established sites such as Google and Yahoo.

The industrial organization literature has long established that different products can coexist in a market at the same time (see, e.g., [2, 5, 11, 14, 17]). Typically, this is demonstrated in models of vertical (quality) or horizontal (taste) differentiation. A key feature of vertical differentiation models is that a low-quality good must have a lower price than a high-quality good. Otherwise, all consumers would buy the highquality product. However, the price charged to users of search engines is typically zero, with revenues being earned from advertisers. Therefore, consumers do not face a tradeoff between quality and price. Why do lower-quality products survive in such a market?

Similarly, a key result in horizontal differentiation models is that maximum differentiation among products is optimal when users incur quadratic transportation costs [6]. This enables firms to charge higher prices, and leads to higher profits. Since the price is not a strategic variable in the search engine market, what outcome should we expect? 
In this paper, we first consider just vertical differentiation, and show that it is exactly this zero-price feature that allows products of differing qualities to survive in this market. Since the quality of the results from a particular search is inherently stochastic, some users may not be fully satisfied with their search. As the price of sampling multiple products in a single session is close to zero, these users now have an incentive to visit a lower-quality engine. The ability to sample many products quickly and cheaply is a unique feature of information goods on the Internet, and represents a departure from the previous literature on quality differentiation. This phenomenon, which we call "residual demand" for the low-quality product, allows the low-quality product to survive. Then, we consider a model that incorporates horizontal differentiation as well, and show that neither maximum nor minimum differentiation is optimal. There is a tradeoff on optimal location - engines would like to be similar to get residual demand, but not too similar, since it may lead to intense quality competition. Although our model is specific to search engines, our insights generalize to information goods, including news sites such as CNET or the New York Times, and shopbots such as Mysimon (www.mysimon.com) and Shopping.com (www.shopping.com).

Our model is based on two key properties of the market for Internet-based information goods. First, the explicit price paid by the consumers for the use of these products is zero; the primary source of revenue for these products is advertisements. Despite a somewhat depressed online ad market in the past two years, online advertising is still a substantial part of the search engines' revenue stream. For example, Yahoo still earns close to 65 percent of its revenues (about $\$ 1$ billion) through advertisements. With the success of Google (www.google.com) and Overture (www.overture .com) in generating ad revenues via better targeting and technology, the online ad industry grew almost 11 percent and grossed about $\$ 7.3$ billion in 2003 [7]. With the use of rich media (audio and video) and creative ads (contextual ads), almost all online publishers showed growth in their online revenues in 2003 [9, 15]. In fact, search engines are considered the best online ad vehicle. Moreover, due to difficulties involved in micropayments for such content, free digital content exclusively based on advertising revenues will continue to be a large and substantial market.

Second, sometimes users may sample more than one product or service during a single session. As Lawrence and Giles [13] and Bradlow et al. [3] mention, search engines maintain databases that contain only a fraction of the information in the universe. Moreover, they often run different algorithms on their database, so that engine results are inherently stochastic. This often induces a visit to another search engine within the same session, which restarts the search process. Based on actual usage data, Telang and Mukhopadhyay [19] report that users switched to a second engine during 22 percent of search sessions. For example, the rate of switching was 15 percent for those who first went to Yahoo, while it was 31 percent for Infoseek. The statistics from Nielsen/NetRatings (see Figure 1) also suggest that users sample more than one engine when looking for information. These numbers are only for "searchrelated" traffic, and the report notes that "Because a web surfer may visit more than one service, the combined totals exceed 100 percent" [18]. For January 2004, the totals for the top 5 engines alone add up to approximately 123 percent. 


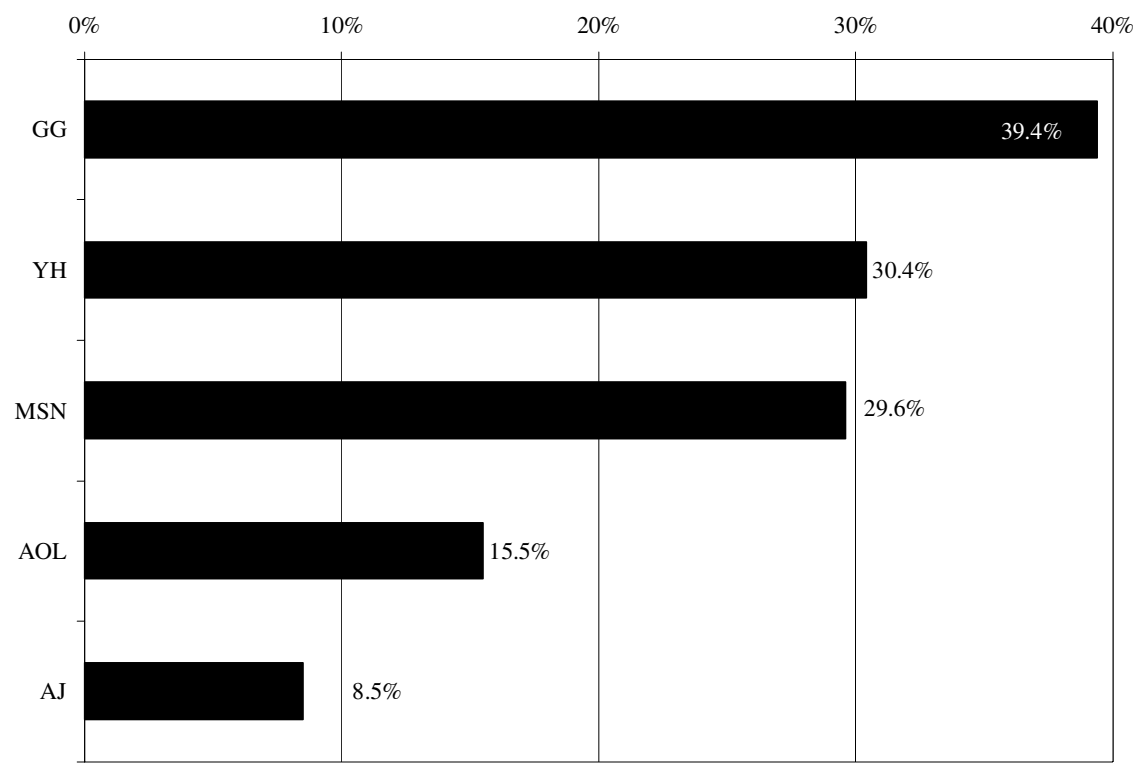

Figure 1. Home and Work Users, Search Engine Reach in January 2004

Source: Nielsen/NetRatings for SearchEngineWatch.com.

Notes: GG_Google; YH_Yahoo; AOL_America Online; AJ—AskJeeves.

\section{Summary of Results and Key Contribution}

We start with a duopoly model of vertical differentiation, in which all users prefer a higher-quality engine to a lower one. We consider sequential entry. In the first period, there is only one firm in the market. An entrant enters in the second period and competes with the incumbent. Since users incur no cost for using an engine, all users sample the higher-quality product first. In previous vertical differentiation models, such as Moorthy [14] and Shaked and Sutton [17], the lower-quality product has a lower price and hence captures some of the market. If both products had the same price, no lower-quality good could exist in this circumstance. In our model, some proportion of consumers go on to sample a lower-quality product because quality is stochastic. In other words, on average, the high-quality engine yields good results. However, it may not yield the site a user needs for a given search term. A different engine, even one with lower average quality, may find a different site. We show that this residual demand enables a lower-quality product to survive.

To focus on rapid improvement in technology, we allow the entrant to have an advantage in technology, modeled as a cost advantage. A late entrant can enter with the newest technology, whereas an incumbent is locked into an earlier technology. ${ }^{2}$ Interestingly, we show that if the entrant's cost advantage is low, the incumbent overinvests in quality in the first period, and remains the high-quality provider in the 
second period, with the entrant offering a low quality. For example, many engines (e.g., Lycos) that entered after Yahoo were considered lower-quality engines. ${ }^{3}$ Conversely, if the entrant has a large advantage in technology, the incumbent may choose to not compete head-on and underinvests in quality in the first period. The entrant then takes over as the high-quality provider, much as Google did over Yahoo.

In practice, we expect product positioning (that is, horizontal differentiation) to matter in the search engine market as well. Therefore, we consider a model with both vertical and horizontal differentiation. Since sequential entry models may be intractable in this context (see [16]), we consider a structure in which engines first choose their location (or differentiation strategy) and then choose their quality. We show that, with quadratic transportation costs (a standard assumption in the literature), engines want to be neither maximally nor minimally differentiated. Moreover, residual demand reduces this differentiation even more. Therefore, engines have incentives to be "similar," but not the same. We summarize the key contributions of our paper as:

- We introduce the concept of "residual demand" and show that the presence of such demand changes the search engine vendor firm's strategy in important ways. Significantly, residual demand leads to higher overall demand for engines and hence more opportunities for product proliferation. Therefore, a lower-quality engine may still be profitable even without any horizontal differentiation from the dominant player.

- We provide a model of both vertical and horizontal differentiation in the search engine market, where pricing is not a strategic variable. To our knowledge, there is no other model of competition between firms where the price is set to zero in this manner. Although television programming has a similar zero-price feature, much of the work in this area focuses on policy issues rather than competition (see, e.g., [1]).

\section{Model of Quality Differentiation}

TWO FIRMS COMPETE IN QUALITY IN THE MARKET. We interpret quality as the ability of the engine to provide results or information that satisfies a user. For example, for search engines, this definition of quality includes the two common attributes of quality: (1) the quantity of information retrieved, and (2) its relevance to the user. Our definition of quality may be interpreted as a reduced-form notion that encompasses both of these attributes. A higher quality is more valued by the user because it implies either a higher quantity of information, or information of greater relevance, or both. We assume that the qualities of the firms are common knowledge.

Using the product requires both time and effort on the part of a consumer. Therefore, the lower the quality of a product, the less likely it is that a consumer will be willing to invest his or her time and effort. Hence, we model demand as increasing in quality. If a firm is a monopolist and offers quality $q$, the demand in a given period is $D(q)$. We assume that the demand curve is linear, with $D(q)=a+b q$, where $a \leq 0$ (so that a firm offering a zero quality has no customers) and $b>0 .{ }^{4}$ 
Our model encompasses two periods, 0 and 1 . The demand curve is assumed to be the same in each period. In Period 0, Firm 1 (the incumbent) is the only firm in the market, and chooses a quality level $q_{0}$. In Period 1, Firm 2 (the entrant) enters, and offers quality $q_{2}$. The incumbent may increase its quality from $q_{0}$ to $q_{1}$. However, we assume that quality cannot decrease, so that $q_{1} \geq q_{0}$.

Most digital products require an up-front investment in hardware and software development [12]. The firms need to set up the infrastructure of Web servers, content gathering, and provision. For example, in the case of search engines, Web robots crawl the World Wide Web and index the information in a local database. When a user inputs a search term, queries are run on the local database and results are returned. Once the up-front investments have been made, the marginal costs are relatively low. Therefore, we assume that Firm 1 can at least remain at its original quality $q_{0}$ by incurring small marginal costs. Hence, we restrict $q_{1}$ to be at least as high as $q_{0}$.

Firm 1 has a cost function $C(q)$ assumed to be strictly increasing and strictly convex. Firm 2 has a cost function $\lambda C(q)$, where $\lambda$ ranges between zero and one. When $\lambda=1$, neither firm has a cost advantage. When $\lambda<1$, the entrant has a cost advantage. $\lambda$ captures the idea that the costs associated with technology are constantly falling (or, alternatively, that the technology itself is improving). The incumbent, since it established its infrastructure in Period 0, is locked into the old technology. These are onetime setup costs that enable repeated use of the product. The marginal cost of additional users is low in practice. We assume it to be zero.

On any given visit to a particular engine, a user may not be fully satisfied with the outcome. The higher the quality $q$ of the engine, the greater the chance that the user will be satisfied. We assume that for a given visit, a user is satisfied with the results with probability $p(q)$. Suppose a user in Period 1 tries out Firm 1 first. Then, with probability $p\left(q_{1}\right)$, the user finds the information she needs and her quest for information ends. With probability $\left(1-p\left(q_{1}\right)\right)$, the user is dissatisfied with the information received. Then, if Firm 2's product is of sufficiently high quality, she proceeds to use it. We say that Firm 2 has a "residual demand" in this case; there are some users who used Product 1 who still want to sample Product 2.

To facilitate analytical solutions, we assume that $p(q)=q$, and $C(q)=k q^{2}$. Parameter restrictions are imposed to ensure that chosen quality levels satisfy $0<q<1$. As shown below, interestingly, firms' demand and profit functions are discontinuous, depending on whether the firm has a higher or lower quality than its competitor. Therefore, though equilibria with similar qualitative features exist with more general functions for demand, cost and probability, characterizing these analytically is quite difficult.

Revenues of each firm are directly linked to its demand; we assume that a firm earns advertising revenue of $r$ in each period per consumer that visits it. As noted by Hoffman and Novak [10] and Dewan et al. [6], advertising revenues depend on the number of "hits" a Web site obtains. ${ }^{5}$ Therefore, the profit of an engine can be written as $\pi=D(q) r-k q^{2}$, where $D$ is the demand, and $r$ is the revenue per user. For convenience, we define $c=k / r$, and renormalize the profit function by dividing by $r$ and write it as $\pi=D(q)-c q^{2}$. This renormalization affects the level of profit earned by a 


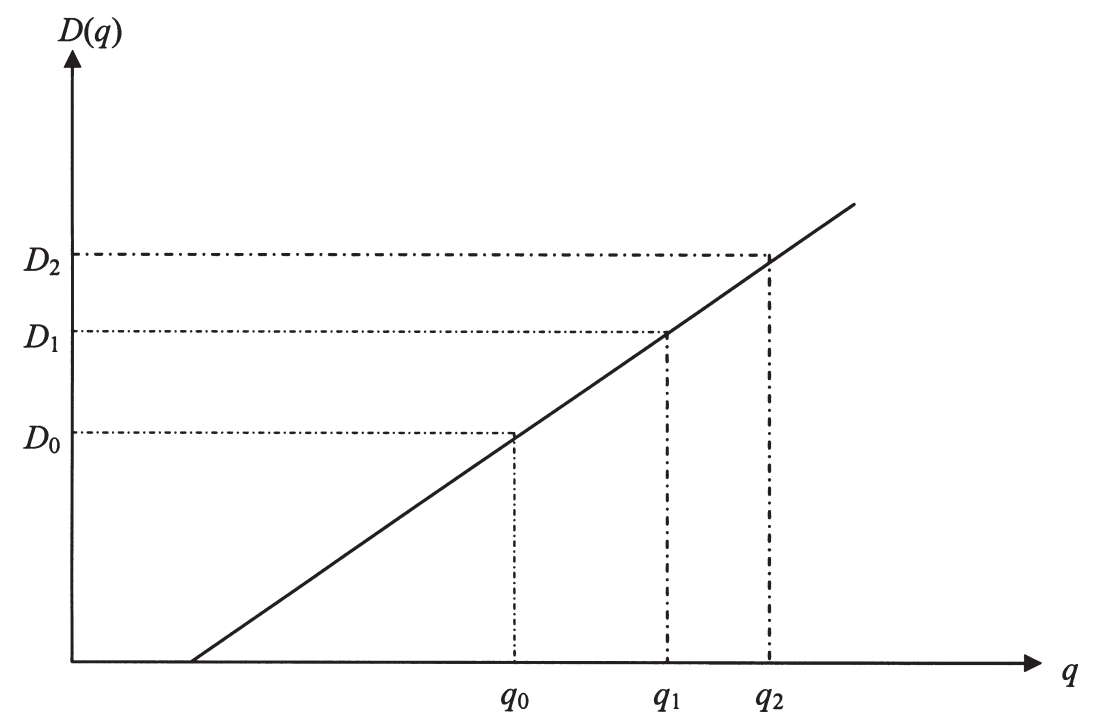

Figure 2. Consumer Demand When $q_{2}>q_{1}>q_{0}$

firm, but not its profit-maximizing quality level (i.e., its strategy). In the analysis below, our main concern is with the strategies of the firms, and whether profits are greater or less than zero. Neither of these is affected by the renormalization.

In Period 0, $D\left(q_{0}\right)=a+b q_{0}$ consumers use Firm 1, as it is the only product in the market. Entrant enters in Period 1. Any user may be dissatisfied with the results offered by her first-choice product. As mentioned before, all dissatisfied users will switch to the other product if its quality is high enough. To illustrate the demand of both firms, consider the following two cases.

\section{Case 1}

Let $q_{2}>q_{1}>q_{0}$. Then, Firm 2 has the high-quality product and Firm 1 the low-quality one in Period 1. Figure 2 shows the demand curve.

Consider the demand faced by Firm 2 in Period 1 . The users $D_{2}-D_{0}=b\left(q_{2}-q_{0}\right)$ are all new users in this period (that is, they did not use any product at Period 0 ). All new users will use the higher-quality product first. In this case, since $q_{2}>q_{1}$, all these users visit Firm 2 as their first choice in Period 1. In addition, all of the users $D_{0}$ who visited Firm 1 in Period 0 will also switch to the higher-quality entrant in Period 1. Hence, the total demand for Firm 2 is simply $a+b q_{2}$. With probability $\left(1-q_{2}\right)$, each of these users will be dissatisfied with the output of Firm 2. Users in the region $\left[D_{1}, D_{2}\right]$ end their search, since $q_{1}$ is too low for them. The remainder will switch to Firm 1. Hence, the demand for Firm 1 is $D_{1}=\left(1-q_{2}\right)\left(a+b q_{1}\right)$. Now, the profit of Firm 2 is

$$
\pi_{2}^{1}\left(q_{0}, q_{1}, q_{2}\right)=D_{2}\left(q_{0}, q_{1}, q_{2}\right)-C\left(q_{2}\right)=a+b q_{2}-\lambda c q_{2}^{2},
$$


where we use the normalization $c=k / r$. The profit of Firm 1 is the sum of its profits in Periods 0 and 1, with no discounting. The cost of Firm 1 is $c q_{0}^{2}$ in Period 0 , and $c\left(q_{0}^{2}\right.$ $-q_{0}{ }^{2}$ ) in Period 1 , for a total cost of $c q_{1}{ }^{2}$. Its demand in Period 0 is $a+b q_{2}$, and demand in Period 1 is given by $D_{1}$. Hence,

$$
\pi_{1}^{f}\left(q_{0}, q_{1}, q_{2}\right)=a+b q_{0}+\left(1-q_{2}\right)\left(a+b q_{1}\right)-c q_{1}^{2}
$$

\section{Case 2}

Now Firm 1 is the high-quality one in Period 1, and Firm 2 the low-quality one. In particular, suppose that $q_{1}>q_{2}$ and $q_{1} \geq q_{0}$, where $q_{0}$ can be greater or less than $q_{2}$. Then, the first- and second-choice demands for the products change in an appropriate manner. The profit function of Firm 1 is now determined to be

$$
\pi_{1}^{t}\left(q_{0}, q_{1}, q_{2}\right)=\left(a+b q_{0}\right)+\left(a+b q_{1}\right)-c q_{1}^{2} .
$$

Notice that, in this situation, all users who used Firm 1's product in Period 0 come back to it as the first choice in Period 1, since it is the higher-quality firm. Hence, there is no residual demand for Firm 1: any user dissatisfied with Firm 2 has already tried Firm 1's product and found it unsatisfactory. The profit function of Firm 2 is

$$
\pi_{2}^{f}\left(q_{0}, q_{1}, q_{2}\right)=\left(1-q_{1}\right)\left(a+b q_{2}\right)-\lambda c q_{2}^{2}
$$

If $q_{2}=q_{1}$, then firms are assumed to share new customers equally (that is, those consumers in the region $\left.b\left(q_{1}-q_{0}\right)\right)$.

Notice the discontinuity in the profit functions associated with being a high-quality instead of a low-quality provider. ${ }^{6}$ This discontinuity has the same flavor as the discontinuity in the Bertrand model of duopoly. The difference is that, in a standard Bertrand model, if one firm has a higher price than the other, its demand falls to zero. In our model, if one firm offers lower quality than the other, its demand does fall, but can remain strictly positive because no firm can perfectly satisfy its consumers. Dissatisfied consumers will visit other products or services. This feature of this market, we argue, may allow many firms of differing qualities to remain in the market, even though the price discrimination is not possible.

The solution concept we use is pure strategy subgame-perfect equilibrium. Subgameperfection is natural here, since it is a sequential game. Even in the second period, pure strategy equilibrium exists, so we do not consider mixed strategies.

First, we show that, in equilibrium, Firm 1 sets $q_{1}=q_{0}$. Suppose, instead, that $q_{1}>$ $q_{0}$. Then, Firm 1 incurs a total cost of $c q_{1}^{2}$ over the two periods. Increasing first-period quality to $q_{1}$ leads to additional demand (hence additional revenue) in Period 0 , at no extra cost (since the amount $c\left(q_{1}^{2}-q_{0}^{2}\right)$ is incurred anyway in Period 1). Hence, a strategy that has $q_{0}<q_{1}$ is dominated by one that has $q_{0}=q_{1}$.

Note that the proposition below holds for all values of $\lambda$. All proofs are in the Appendix. 
Proposition 1 (Incumbent Quality Choice): In equilibrium, the incumbent chooses the same quality in both periods, so that $q_{1}=q_{0}$.

For the rest of the paper, we set $q_{1}=q_{0}$. Therefore, in equilibrium, there will be new users in Period 1 (that is, users who did not attempt a search in Period 0) only if $q_{2}>q_{1}$.

Next, we define the quality levels the incumbent and entrant would offer if each were a monopolist. Let $q_{1}{ }^{m}$ be Firm 1's monopoly level, and $q_{2}{ }^{m}$ that of Firm 2. Then, $q_{1}{ }^{m}$ solves the problem $\max _{q} \pi_{1}(q)=2(a+b q)-c q^{2}$. The first-order condition is $2 b q-$ $2 c q=0$, from which we have $q_{1}{ }^{m}=b / c$. The monopoly level of the entrant, $q_{2}{ }^{m}$, is found as the solution to $\max _{q} \pi_{2}(q)=a+b q-\lambda c q^{2}$. The first-order condition is $b q-$ $2 \lambda c q=0$, from which we have $q_{2}{ }^{m}=b / 2 \lambda c<q_{1}{ }^{m}$. We maintain the following assumptions on the parameters:

Assumption 1: (i) $\lambda c>(a+b)$. (ii) $a+\left(b^{2}(1-b / c)\right) / 4 c>0$.

Part (i) of the assumption ensures that the cost stays within a range such that the entrant will not be profitable at a quality of 1 . Therefore, it will choose a quality strictly less than 1 . Since $\lambda \leq 1$ in this model, this also ensures that the incumbent will not choose a quality of 1 . Part (ii) ensures that the entrant makes a strictly positive profit when $\lambda=1$, the incumbent offers its monopoly quality $q_{1}{ }^{m}=b / c$, and the entrant plays a best response. If $\lambda$ is strictly less than 1 , then this condition is more likely to be satisfied, so it is sufficient to assume at $\lambda=1$. As explained below, this condition is required in Proposition 2.

\section{No Cost Advantage for Entrant}

FIRST, CONSIDER THE CASE OF $\lambda=1$; that is, the entrant has no cost advantage over the incumbent. Under the assumptions made, we show that the incumbent, Firm 1, will offer its monopoly quality level, and the entrant will be the follower at Period 1. In this situation, the presence of the entrant does not affect Firm 1 at all. It continues to offer a monopoly quality and earn a monopoly profit. However, Firm 2 still finds it profitable to enter the market because of demand from the customers of Firm 1 that are dissatisfied with the results of their search query. For example, Lycos and Infoseek, which entered the market after Yahoo, are widely perceived as lower-quality engines.

Proposition 2 (Low-Quality Entrant): Suppose the entrant does not have a cost advantage. In equilibrium, the incumbent engine offers the monopoly quality $\left(q_{1}^{m}=b / c\right)$ in both periods and the entrant chooses a lower quality $q_{2}=(b(1-$ $\left.\left.q_{1}^{m}\right)\right) / 2 c<q_{1}^{m}$.

That is, despite there being no price difference across the two products, the lowerquality product also survives in equilibrium. This is because of the residual demand. If there is no residual demand, then (absent horizontal differentiation, which we consider in the fourth section) a lower-quality engine cannot survive in the market. For the consumer, both products have the same price (zero). Hence, the market cannot sustain a lower-quality product unless there is residual demand from the higher-quality firm. 
If there is one "very" high-quality engine in the market, residual demand will be negligible, and the duopoly is unsustainable. The high-quality engine becomes a monopoly. Part (ii) of Assumption 1 ensures that, when the incumbent offers a monopoly quality, the entrant can enter the market at a low-quality level and still make a positive profit.

To demonstrate the nature of the strategic interaction between the firms, we consider a numeric example and depict the best response of the entrant to every possible $q \in[0,1]$ that the incumbent might offer. This example represents a base case, and all other examples in the paper consider variants of the same parameters. The parameters for this example are $a=-0.05, b=1, c=2, \lambda=1$.

Figure 3 demonstrates the reaction function of Firm 2, given a quality level $q_{1}$ chosen by Firm 1 . When $q_{1}$ is low, close to zero, Firm 2 has the high-quality product, and chooses its monopoly level, $q_{2}{ }^{m}=0.25$. As $q_{1}$ rises to just above 0.25 , Firm 2 prefers to compete with Firm 1 , and chooses $q_{2}=q_{1}+\varepsilon$. However, at $q_{1}=\hat{q}(0.43$ in this example), Firm 2 is indifferent between being a high-quality and low-quality provider. For $q_{1} \leq \hat{q}$, Firm 2 has the low quality, and its quality falls as $q_{1}$ increases. Finally, when $q_{1}$ rises above 0.6 , Firm 2 exits the market altogether (i.e., sets $q_{2}=0$ ).

The reaction function, therefore, has two points of discontinuity. The first is at $\hat{q}$, as mentioned before. The second occurs when Firm 1 chooses a quality against which Firm 2 can no longer make a positive profit. Since Firm 1 sets $q_{0}=q_{1}$, we can model the best response of Firm 1 as choosing an optimal point on Firm 2's reaction function. That is, Firm 1 computes its profit for each point on the reaction function, and chooses the quality $q_{1}$ at which its profits are maximized.

In the example, when Firm 1 chooses $q_{1}=q_{1}{ }^{m}=b / c=1 / 2$, Firm 2 chooses $q_{2}=0.125$ $<q_{1}$, which is the equilibrium described in Proposition 2. Notice that when Firm 1 chooses $q_{1}=0.43$, Firm 2 is exactly indifferent between being a low-quality $\left(q_{2}=\right.$ $0.14)$ and high-quality provider $\left(q_{2}=0.43+\varepsilon\right.$ for some small $\left.\varepsilon>0\right)$.

Define the critical quality threshold to be the quality level of the incumbent such that the entrant is indifferent between offering a lower-quality and a higher-quality product. This threshold is $\hat{q}$ in Figure 3.

\section{Entrant Cost Advantage}

As shown in Proposition 2, when there is no cost advantage to the entrant, the incumbent is the high-quality firm in equilibrium. However, this effect can be dominated by a high-cost advantage for the entrant. That is, under some conditions, the entrant can also be the high-quality firm in equilibrium. Note that if the incumbent and entrant both have access to the same technology in the second period, the results of the previous section will continue to hold.

In this section, we analyze the effect of a cost advantage to the entrant $(\lambda)$. The incumbent in our model has a first-mover advantage. By choosing $q_{1}>\hat{q}$ (where $\hat{q}$ is the quality level at which the entrant is indifferent between being high quality or low quality, as defined previously), it can always force the entrant to offer low quality in equilibrium. Hence, the effects of the parameter $\lambda$ can be analyzed through its effect 


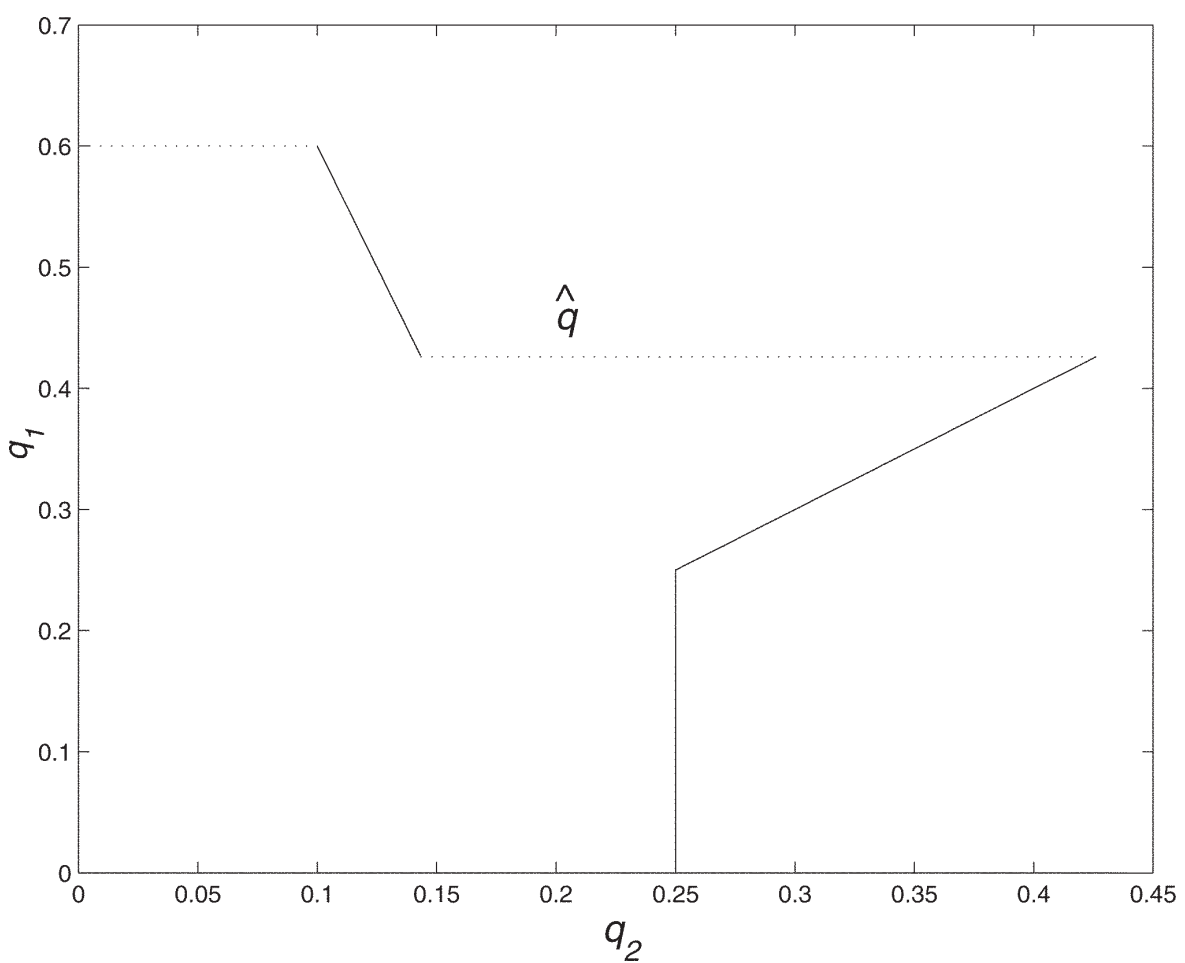

Figure 3. Reaction Function of the Entrant

on $\hat{q}$. If $\hat{q}$ increases, this is costly for the incumbent: it has to offer higher quality than otherwise, to force the entrant to offer a low-quality product. If $\hat{q}$ falls, the incumbent is better off. Consider the effect of increasing cost advantage to the entrant. As $\lambda$ falls below $1, \hat{q}$ begins to rise.

Lemma 1: As technology costs $\lambda$ for the entrant fall, the critical quality threshold $\hat{q}$ of the incumbent increases.

Note that since $\hat{q}<q_{1}{ }^{m}$ at $\lambda=1$, there will be a value of $\lambda, \lambda_{m}$, at which $\hat{q}=q_{1}{ }^{m}$. Until this value of $\lambda$ is reached, it is clear that the equilibrium of Proposition 2 will continue to hold. The incumbent offers higher quality, and the entrant offers lower quality.

The entrant will offer a real competitive threat to the incumbent only for $\lambda<\lambda_{m}$. When $\hat{q}>q_{1}{ }^{m}$, it becomes costly for the incumbent to force the entrant to offer low quality. The incumbent now compares its own profit as high quality (as a leader, it must offer $\hat{q}$ now) and as low quality (where it plays some best-response strategy, with the entrant offering higher quality).

Note that the incumbent offers $q_{1}=\hat{q}>q_{1}{ }^{m}$. In other words, the incumbent has to offer higher than monopoly quality when the entrant enters with lower costs. This also outlines the strategic advantage the incumbent has. It can offer higher quality and force the entrant to become a low-quality firm even though the entrant has a cost advantage. Also, note that since $q_{0}=q_{1}$, the incumbent overinvests in quality in the 
first period itself to be a quality leader. Tyagi [21] shows that the firm with lower costs occupies the most desirable location. Our results extend this result to a two-period setting with differential qualities. In the two-period setting, as long as the entrant does not have too high a cost advantage, the incumbent can overinvest in quality and remain the quality leader.

Eventually, when the entrant's cost advantage becomes very high, the incumbent has no option but to offer lower quality. For example, with the emergence of Google, Yahoo is a lower-quality player and generates less traffic than Google. We show first that, when the entrant offers high quality, it offers its own monopoly quality level, $q_{2}=b / 2 \lambda c$.

Proposition 3 (High-Quality Entrant): For a high cost advantage $\left(\lambda<\lambda_{l}\right)$, the entrant becomes a high-quality firm in Period 1 and offers its own monopoly quality level. The incumbent is now a low-quality firm and offers $q_{1}=(b / c)-$ $\left(b^{2} / 4 \lambda c^{2}\right)$ in both periods.

Therefore, when the entrant is a high-quality firm in equilibrium, the quality of the incumbent is increasing in $\lambda$. As $\lambda$ falls, $q_{2}$ rises. The demand for the incumbent is now the residual demand created by dissatisfied users of Firm 2. As this demand shrinks, the quality offered by Firm 1 falls as well. Therefore, the prospect of falling technology costs in Period 1 affects the quality offered by the incumbent in Period 0.

If the incumbent believes that the entrant will compete with a much superior technology in the next period, then, despite being a first-mover, it prefers to offer a lower quality in Period 0 itself. The incumbent, therefore, strategically underinvests in quality. It anticipates competition from a low-cost entrant and chooses a low quality in the first period itself.

Therefore, with sequential entry and quality differentiation, an incumbent can exhibit both high and low investment, depending on the cost structure of the entrant. An incumbent who expects to be a dominant high-quality player in the future tends to overinvest in infrastructure. On the other hand, an incumbent who does not expect to be the leading player in the market tends to underinvest in infrastructure.

If $\lambda$ is sufficiently low, then $\hat{q}$ can be substantially higher than $q_{1}{ }^{m}$. At this point, exercising the first-mover advantage is costly to the incumbent, and it may prefer to be a low-quality firm in equilibrium.

\section{Horizontal and Vertical Differentiation}

IN THIS SECTION, WE CONSIDER THE EFFECTS of residual demand when there is both horizontal and vertical differentiation. The previous section outlined the importance of residual demand in allowing the existence of a low-quality engine. Here, we highlight how firms' horizontal differentiation strategy changes in the search engine market as a result of residual demand.

With horizontal differentiation, we look at firms choosing location simultaneously rather than sequentially. As Prescott and Visscher [16] note, the sequential entry model 
with firms choosing locations and then prices does not admit an analytic solution. Interestingly, their numeric solution in the duopoly case also yields maximal differentiation, which is the standard result in the simultaneous model as well.

First we model firms' choices assuming there is no residual demand, and then we show how residual demand changes their strategies. We now assume that users are heterogeneous in terms of their preferences. For each user, the utility from a given engine depends on how close it is to his particular taste. ${ }^{7}$ In particular, a user may care about the interface, nature of results, presentation of results, or other such attributes. We assume the taste parameter is between 0 and 1 . Users are uniformly located on the line segment $[0,1]$, and a user's location determines his or her taste. A user faces a quadratic "transportation" cost (i.e., a disutility incurred if an engine does not exactly match his or her tastes) for using an engine at any other location. ${ }^{8}$ As before, we assume that the price for using an engine is zero, and the utility of a user is linear in quality. The net utility to a user from an engine of quality $q$ located at a distance $d$ from the user is $u(q, d)=q-d^{2}$. Note that, analogous to the previous section, we could set this to $a+b q-d^{2}$. Since the scale of the transportation cost is arbitrary, without loss of generality we can set $b=1$. Setting $a=0$ does not affect the qualitative nature of the results; a value $a<0$ would merely imply a minimum quality an engine must have to obtain a nonzero demand.

The engines first choose their locations (i.e., how differentiated they are) and then their respective qualities. The previous literature (see [5]) has established that, in the presence of quadratic transportation costs, products are maximally differentiated in a duopolistic market structure. To simplify the analysis, we assume that engines are symmetric in terms of their cost structure. Suppose Engine 1 locates at a distance $x$ from the left and offers quality $q_{1}$ and Engine 2 locates at a distance $y$ from the right and offers quality $q_{2}$. Figure 4 clarifies this.

We also make the usual assumption that the market is fully covered in equilibrium, so that each consumer visits an engine. First, suppose there is no residual demand. In equilibrium, the market of each engine consists of the users close to it. There will be some consumer (denoted by the solid dot in Figure 4) between the locations of the two engines, who is indifferent between the two. Suppose this indifferent customer is located at a distance $t$ from Engine 1. Then, his or her distance from Engine 2 is $1-(x$ $+y)-t$. Hence, his or her utility from Engine 1 is $q_{1}-t^{2}$, and from Engine $2 q_{2}-(1-$ $(x+y)-t)^{2}=q_{2}-(1-(x+y))^{2}-t^{2}+2(1-x-y) t$. We find $t$ by equating these utilities, which yields

$$
t=\frac{1-(x+y)}{2}+\frac{q_{1}-q_{2}}{2(1-x-y)}
$$

Then, the demand for Engine 1 is $D_{1}=x+t$ and for Engine $2 D_{2}=1-(x+t)$. As before, we assume the normalized (relative to advertising revenue) cost of quality for both engines is $c q^{2}$. Therefore, the profit functions are

$$
\pi_{1}=x+t-c q_{1}^{2} \quad \text { and } \quad \pi_{2}=1-(x+t)-c q_{2}^{2} .
$$




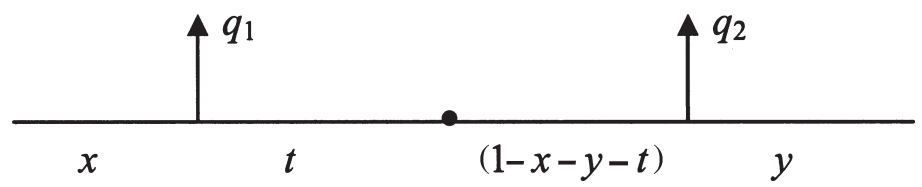

Figure 4. Horizontal Differentiation

Substitute $t$ into the profit equations and take the first-order conditions. This yields the optimal qualities $q_{1}=q_{2}=1 / 4 c(1-x-y)$.

If $x=y=0$, we have maximal differentiation. In this case, the market would be covered only if $q_{1}=q_{2} \geq 1 / 4$. This requires that $c \leq 1$. Further, the restriction $q_{1}, q_{2}<$ 1 requires that $c>1 / 4$. Hence, we assume $c \in(1 / 4,1]$.

Now, substitute $q_{1}$ and $q_{2}$ into the profit equations, and solve for optimal locations $x$ and $y$. This yields $x+y=\left(1-1 /\left(2^{2 / 3} c^{1 / 3}\right)\right)$. Since the firms are symmetric, we consider only the symmetric solution $x=y=1 / 2\left(1-1 /\left(2^{2 / 3} c^{1 / 3}\right)\right)$.

Now, maximal differentiation obtains if $x=y=0$. This requires $c=1 / 4$. Hence, for all $c>1 / 4$, maximal differentiation fails to obtain. Further, it is clear that $x, y<1 / 2$, so that minimal differentiation also fails to obtain. Therefore, we have a result that is in contrast to standard pricing models. In the case of the search engine market, we get neither maximal nor minimal differentiation. Note that this result is without residual demand.

\section{Differentiation with Residual Demand}

We next consider the effects of residual demand on firms' strategies. Now, users of an engine may switch to the other engine if they are dissatisfied with the results provided by the first engine. For example, users from Engine 2 will be willing to use Engine 1 as long as their distance from Engine 1 is no higher than $\sqrt{q_{1}}$. Users at a distance further than $\sqrt{q_{1}}$ from Engine 1 will obtain a negative utility from the engine and not use it. Thus, there are two cases to consider.

Suppose $q_{1}<(1-x)^{2}$. Then, the user located at 1 (extreme right on the line in Figure 4) obtains a negative utility from Engine 1, so will not use it. All users within a distance $\sqrt{q_{1}}$ of Engine 1 are willing to use it. Of these, users to the left of Engine 1, and those within a distance $t$ on the right, use it as a first choice. This comprises a total mass $x+t$. The remaining users of mass $\sqrt{q_{1}}-t$ use Engine 2 as the first choice, but will switch to Engine 1 if dissatisfied. Since the probability that they will be dissatisfied with Engine 2 is still $1-q_{2}$, the residual demand generated for Engine 1 is (1$\left.q_{2}\right)\left(\sqrt{q_{1}}-t\right)$. Therefore, the total demand for Engine 1 in this case is $D_{1}=x+t+(1-$ $\left.q_{2}\right)\left(\sqrt{q_{1}}-t\right)=x+\left(1-q_{2}\right) \sqrt{q_{1}}+t q_{2}$.

If, on the other hand, $q_{1}>(1-x)^{2}$, then even the user located at 1 obtains a positive utility from Engine 1. In this case, all dissatisfied users of Engine 2 will switch to Engine 1. Since a mass $1-(x+t)$ of users use Engine 2 as their first choice, the residual demand for Engine 1 is $\left(1-q_{2}\right)(1-(x+t))$. Hence, the total demand for Engine 1 in this case is $D_{1}=x+t+\left(1-q_{2}\right)(1-(x+t))=1-(1-(x+t)) q_{2}$. Similarly, the total demand for Engine 2 can be expressed as 


$$
D_{2}=\left\{\begin{array}{lll}
y+\left(1-q_{1}\right) \sqrt{q_{2}}+(1-(x+y+t)) q_{1} & \text { if } & q_{2} \leq(1-y)^{2} \\
1-(x+t) q_{1} & \text { if } & q_{2} \geq(1-y)^{2}
\end{array}\right.
$$

Given the demands, the profits for each engine $i$ can be written as $\pi_{i}\left(q_{1}, q_{2}, x, y\right)=D_{i}-$ $c q_{i}^{2}$.

As before, consider the two-stage game: at Stage 1, engines simultaneously choose their locations (i.e., their differentiation strategies), and at Stage 2, they simultaneously choose quality levels. In principle, this game can be solved in a similar manner to the one without residual demand. First, consider Stage 2, with locations already fixed. The first-order conditions for the profit functions yield the optimal quality choices. These can then be substituted back into the profit functions, and the optimal locations determined from that. However, with residual demand, even the qualities cannot be obtained in closed form. ${ }^{9}$

Instead, we isolate the effect of residual demand in the following manner. Suppose both engines locate at their optimal points when there is no residual demand. We show that the presence of residual demand drives them closer together if costs are sufficiently high, and further apart if costs are sufficiently low.

Proposition 4 (Residual Demand and Horizontal Differentiation): There exists a $\hat{c}$ between 0.25 and 1 such that, if $c>\hat{c}$, residual demand leads to less horizontal differentiation, and if $c<\hat{c}$, it leads to greater horizontal differentiation between search engines.

Although we cannot determine the equilibrium of the game in closed form, we can compute a numeric solution for any value of $c$. Numerically, we can also determine that $\hat{c} \approx 0.344$ in Proposition 4 .

To obtain some insight into the solution, we plot the equilibrium values of location $x$ and quality $q$ with respect to cost $c$ both with and without residual demand. We show these values in Figure 5, which has $c$ on the $X$-axis and qualities and locations on the $Y$-axis. The thick lines indicate the residual demand case, and the dotted lines indicate the case without residual demand.

The top two lines in Figure 5 denote quality $(q)$ and the bottom two lines denote location $(x)$. Note that once $c>0.344$, the differentiation decreases with residual demand (i.e., $x$ increases) and quality increases with residual demand (i.e., $q$ also increases). As one expects, the equilibrium quality decreases with higher cost, but at a much lower rate when there is residual demand.

What is the intuition for such a result? A higher cost for quality leads to lower qualities in equilibrium. But when residual demand exists, this has the effect of increasing the residual demand for each firm (since a greater proportion of users will be dissatisfied with their first search). This in turn provides an incentive for the engines to move to the center to grab as many dissatisfied users as possible. Also, since the residual demand consists of users who are at a greater distance than an engine's primary users, an engine has an incentive to increase its quality a little (compared to the 


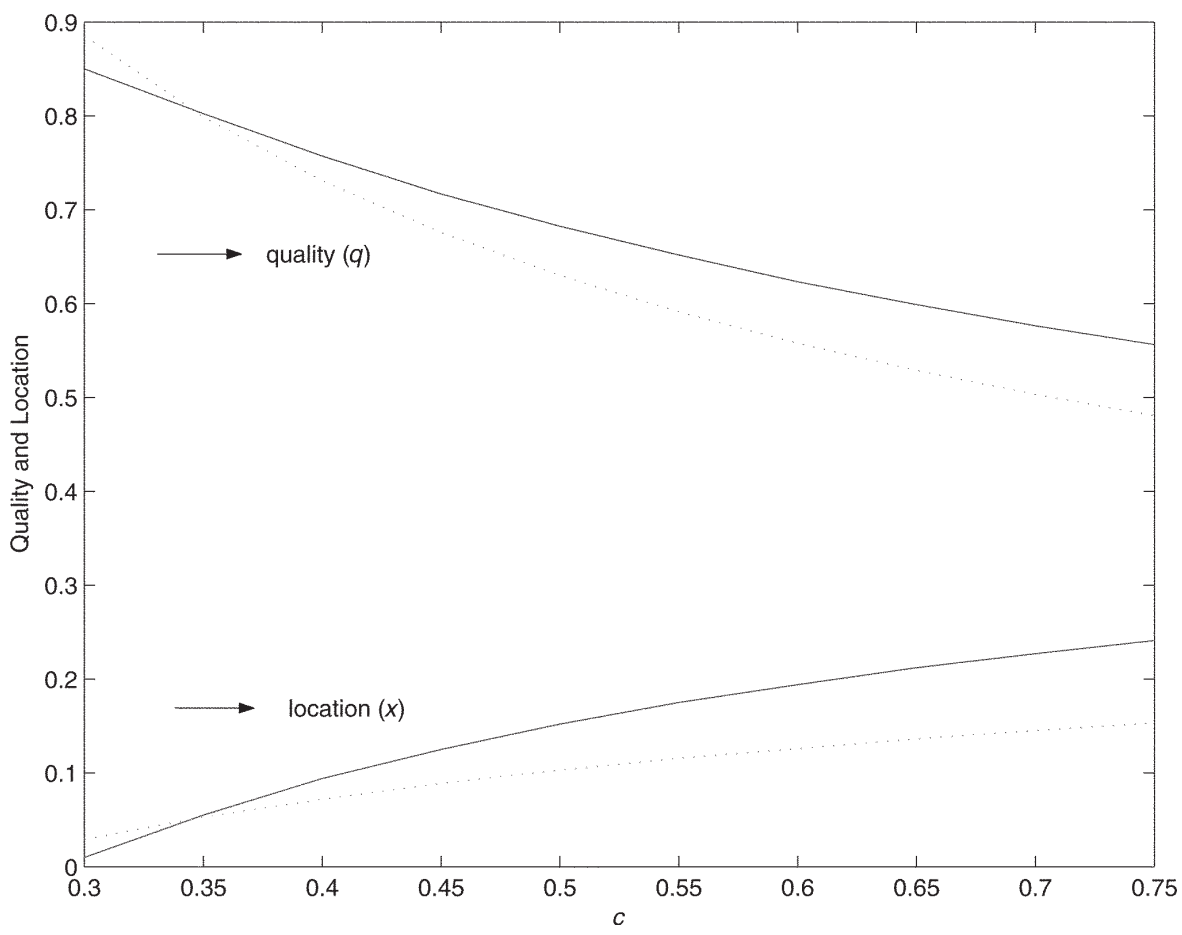

Figure 5. Cost Versus Quality and Location With and Without Residual Demand

case of no residual demand) to capture more of the residual market. Therefore, with residual demand and horizontal differentiation, we observe a higher level of quality than otherwise, and less differentiation.

What is the implication of this result? Although it is difficult to empirically verify the horizontal differentiation strategy of engines, cursory observation supports this hypothesis. In terms of look and feel, and presentation of results, and even type of results, all major engines are somewhat "similar." Moreover, the major engines do not try to differentiate across different search categories, although they may be better at retrieving results from one category than another [3]. Since pricing is not an option, the desire to attract a competitor's users restrains the engines from differentiating maximally. Therefore, we should not expect strong horizontal differentiation among major engines.

Finally, we briefly comment on asymmetric cost structures in this setting. For example, suppose Engine 1 has cost $c_{1}$ and Engine 2 has cost $c_{2}>c_{1}$. All else being equal, a lower cost for Engine 1 implies that, in equilibrium, Engine 1 will have higher quality. This, in turn, suggests that Engine 2 has less incentive to locate close to Engine 1. Hence, in equilibrium, an inferior quality engine (Engine 2) would like to differentiate more from Engine 1, and the engines will locate further apart. 


\section{Conclusion}

WE SHOW THAT QUALITY DIFFERENCES CAN EXIST in a market even when the consumer is paying the same price (zero, for Internet information goods) for all goods. New entrants may enter with low quality, and be viable in the market. This is because, in any given search session, some proportion of users will sample more than one product. This leads to a residual demand for lower-quality products that creates room for more firms to enter the market. Vertical differentiation as a result of this residual demand is different from that considered in the previous literature, where lower prices are used to sustain low-quality products.

The phenomenon of multiple product sampling extends to many information goods on the Internet, including search engines, shopbots, and news sites. Some users regularly visit more than one news site, even for the same news item. Our results extend more generally to all such goods, where the quality of content or service provided is probabilistic in nature and the consumer can engage in product sampling at little cost.

Of course, a firm in such a market is aware that some visitors to its site will soon be consulting a competitor. Hence, by either placing a direct link to a competitor (perhaps in the form of an advertisement), the firm can accrue additional revenue. This phenomenon is evidenced among search engines, for example, with Yahoo and Netscape, which offer links to many other search engines. Firms may even benefit from partnering with other firms so that when a user switches, the switch is to a partner in the same family (e.g., Yahoo and Google earlier, or Lycos and Hotbot). ${ }^{10}$

We also demonstrate that the desire to attract a competitor's users provides firms with an incentive to locate closer to each other. In other words, major engines have fewer incentives to differentiate, and this differentiation decreases with residual demand. Clearly, managers should take into account the phenomenon of residual demand when devising quality and differentiation strategy. By modeling horizontal and vertical differentiation jointly, we provide a comprehensive analysis of the search engine market structure. Without residual demand and horizontal differentiation, we can expect a monopolistic market where one engine will dominate.

Finally, our model also considers the role of new technology. For example, Google is considered a top engine because of the new technology it uses in indexing pages (www.google.com/why_use.html). We also show that an incumbent may underinvest or overinvest in quality, depending on the entrant's technology level. Eventually, the market equilibrium depends on a combination of all factors mentioned above. Hence, today we see a number of firms in the content provider market that capture some traffic without being either a first-mover or having a higher quality than competitors. Due to residual demand, our model points to the fact that more firms can survive in a market.

One limitation of our analysis is that we consider only a duopolistic market structure, whereas there are several search engines in the market at any given time. While models with multiple firms are less tractable analytically, the intuition obtained from duopoly models does go through. We expect many search engines to have some loyal consumers (so that there is an aspect of horizontal differentiation), and also to benefit 
from residual demand (so that the overall reach of search engines exceeds 100 percent). A future extension should incorporate both these aspects into a model with multiple firms.

Acknowledgments: The authors thank the guest editors and two anonymous reviewers for their valuable suggestions.

\section{Notes}

1. For example, see the comscore Media Metrix top 50 sites for January 2004, available at www.comscore.com/press/release. asp?press $=427$.

2. The issue of new technology and competitive advantage has been studied in the IS literature by, among others, Clemons [4].

3. Quality in this context may be multidimensional. Based on popularity, coverage, precision, and relevance, Lycos ranks lower than Yahoo in most surveys. See www.lookoff.com/ tactics/reviews.php3.

4. Formally, this condition implies that consumers have a different willingness-to-pay for quality. For a fixed quality, consumers who obtain a positive utility from the engine will use it. Suppose, for example, the expected utility to a user of type $\theta$ from using an engine of quality $q$ is $u(\theta, q)=\theta+\alpha+\beta q$, where $\alpha \leq 0, \beta>0$, and $\theta$ is uniformly distributed over $[0,1]$. Then, users in the range $[-\alpha-\beta q, 1]$ will use the engine, leading to a demand curve linear in $q$.

5. Recently, some engines are using auction to sell their advertising space. Moreover, some engines allow information providers to pay more money to be ranked higher in their search results [22]. But even the complex contracts can be simplified to per-user or per-impression rate [6]. As long as engine revenue is some function of its demand, all our results will continue to hold.

6. This discontinuity implies, among other things, that in equilibrium it cannot be that $q_{1}=$ $q_{2}$. If $q_{1}=q_{2}$, each firm has an incentive to increase its quality by $\varepsilon>0$.

7. In this section, we model user's utility, and derive the demand from this.

8. As mentioned by Tirole, the problem is that the "linear-cost model is not very tractable" [20, p. 280]. Hence, we assume a quadratic cost.

9. For example, if $q_{1}<(1-x)^{2}$, we have $\left(d \pi_{1}\right) /\left(d q_{1}\right)=\left(1-q_{2}\right) /\left(2 \sqrt{q_{1}}\right)+\left(q_{2}\right) /(2(1-x-y))-$ $2 c q_{1}$, with a similar expression for $d \pi_{2} / d q_{2}$. Setting both derivatives equal to zero does not lead to a closed-form solution for $q_{1}$ and $q_{2}$.

10. The page www.searchengineworld.com/engine/partners.htm contains a list of current partnerships.

\section{REFERENCES}

1. Beebe, J. Institutional structure and program choices in television markets. Quarterly Journal of Economics, 91, 1 (1977), 15-37.

2. Bhargava, H., and Choudhary, V. Information goods and vertical differentiation. Journal of Management Information Systems, 18, 2 (Fall 2001), 89-106.

3. Bradlow, E., and Schmittlein, D. The little engines that could: Modeling the performance of World Wide Web search engines. Marketing Science, 19, 1 (1999), 43-62.

4. Clemons, E. Market dominance as a precursor of a firm's failure: Emerging technologies and competitive advantage of new entrant. Journal of Management Information Systems, 13, 2 (Fall 1996), 59-76.

5. d'Aspremont, C.; Gabszewicz, J.; and Thisse, J.F. On Hotelling's stability in competition. Econometrica, 47, 5 (September 1979), 1145-1151.

6. Dewan, R.; Freimer, M.; and Zhang, J. Managing Web sites for profitability: Balancing content and advertising. In R.H. Sprague Jr. (ed.), Proceedings of the Thirty-Sixth Hawaii 
International Conference on System Sciences. Los Alamitos, CA: IEEE Computer Society Press, 2002 (available at http://csdl.computer.org/comp/proceedings/hicss/2003/1874/00/ 1874toc.htm)

7. E-commerce report. New York Times, May 10, 2004, 6.

8. Gandal, N. The dynamics of competition in the Internet search engine market. International Journal of Industrial Organization, 19, 7 (2001), 1103-1117.

9. Green, H. What's new in online ads: Improvement. BusinessWeek Online (October 31, 2002) (available at www.businessweek.com/technology/content/oct2002/tc20021031_ 7377.htm).

10. Hoffman, D., and Novak, T. A new paradigm for electronics commerce. Information Society, 13 (January-March 1997), 43-54.

11. Hotelling, H. Stability in competition. Economic Journal, 39, 153 (1929), 41-57.

12. Jones R., and Mendelson, H. Product and price competition for information goods. Working Paper, Stanford University, 1998.

13. Lawrence, S., and Giles, L. Searching the World Wide Web. Science, 280, 3 (1998), 98-100.

14. Moorthy, S. Product and price competition in a duopoly. Marketing Science, 7, 2 (1988), $141-168$.

15. Online news publishers showed gains in 2nd quarter. Wall Street Journal, August 25, 2003.

16. Prescott, E., and Visscher, M. Sequential location among firms with foresight. Bell Journal of Economics, 8, 2 (1977), 378-393.

17. Shaked, A., and Sutton, J. Relaxing price competition through product differentiation. Review of Economic Studies, 49, 1 (1982), 3-13.

18. Sullivan, D. Nielsen NetRating's search engine ratings. Search Engine Watch, February 2004 (available at www.searchenginewatch.com/reports/article.php/2156451).

19. Telang, R., and Mukhopadhyay, T. The drivers of Web portal use. Electronic Commerce Research and Application, forthcoming.

20. Tirole, J. The Theory of Industrial Organization. Cambridge, MA: MIT Press, 1998.

21. Tyagi, R. Sequential product positioning under differential costs. Management Science, 46, 7 (2000), 928-940.

22. Weber, T.A., and Zheng, E. A model of search intermediaries and paid referrals. Working Paper 02-12-01, Department of Operations and Information Management, Wharton School, University of Pennsylvania, Philadelphia, 2002. 
Appendix. Proofs

\section{Proposition 1}

BY ASSUMPTION, IT CANNOT BE THAT $q_{0}>q_{1}$. Suppose, then, that Firm 1 chooses $q_{0}=$ $\tilde{q}$ and $q_{1}=\bar{q}$, with $\bar{q}>\tilde{q}$. Consider the effect of choosing $q_{0}=\bar{q}$ and retaining $q_{1}=\bar{q}$. This has no effect on total cost, which remains $c \bar{q}^{2}$.

We show that equilibrium at Period 1 is unaffected; that is, Firm 2's optimal choice of $q_{2}$ remains the same. Suppose that $q_{1}>q_{2}$. Then, from Equation (4), Firm 2's profit function is unchanged as $q_{0}$ changes. Hence, its optimal response is unchanged.

Next, suppose that $q_{2}>q_{1}$. In this case, from Equation (1), we see that a change in $q_{0}$ does affect the level of profit earned by Firm 2. However, again it does not affect the optimal choice of $q_{2}$. This is observed from the first-order condition, $\left(d \pi_{2} / d q_{2}\right)=$ 0 , which yields the best response to be $q_{2}=(b /(2 \lambda c))$, independent of $q_{0}$. If this $q_{2}<q_{1}$, then, to offer high quality, Firm 2 will have to set $q_{2}=q_{1}-\varepsilon$, for some $\varepsilon>0$, which is again unaffected by $q_{0}$.

Hence, $q_{2}$ remains unchanged, and so equilibrium at Period 1 is unchanged when $q_{0}$ is set to $\bar{q}$ instead of $\tilde{q}$. Now, consider the demand for Firm 1 at Period 0. This increases by $b(\bar{q}-\tilde{q})>0$. Since the cost of Firm 1 does not change, this increase in demand represents an unambiguous increase in profit. Hence, it cannot be an equilibrium for Firm 1 to set $q_{0}<q_{1}$.

\section{Proposition 2}

Clearly, Firm 1 (the incumbent) can do no better than set its monopoly quality level $q_{1}$ $=q_{0}=q_{1}{ }^{m}$. This represents the highest profit it can make, even if Firm 2 (the entrant) were absent. Hence, to show that this is an equilibrium, we only need to show that Firm 2 is playing a best response, and cannot do better by choosing some other $q_{2}$.

Suppose Firm 2 has a lower quality in Period 1. Then, its profit is given by Equation (4). Its best response is found from the first-order condition, $\left(d \pi_{2} / d q_{2}\right)=0$, which yields $q_{2}=\left(\left(b\left(1-q_{1}\right)\right) /(2 \lambda c)\right)$. Substituting for $q_{2}$ in Equation (4), we have $\pi_{2}^{f}=a(1-$ $\left.q_{1}\right)+\left(\left(b^{2}\left(1-q_{1}\right)^{2}\right) /(4 \lambda c)\right.$.

If Firm 2 is higher quality, it must set $q_{2}>q_{1}$. Since $q_{1}{ }^{m}>q_{2}{ }^{m}$, its best response is to set $q_{2}=q_{1}-\varepsilon$ for some $\varepsilon>0$. Hence, from Equation (1) (substituting $q_{0}=q_{1}$ ), $\pi_{2}^{l}=a+$ $b\left(q_{1}+\varepsilon\right)-\lambda c\left(q_{1}+\varepsilon\right)^{2}$. This expression is maximized at $\varepsilon=0$. Consider a decreasing sequence $\varepsilon_{n} \rightarrow 0$, where $\varepsilon_{n}>0$ for each $n$. Since $q_{1}{ }^{m}>q_{2}{ }^{m}$, Firm 2's profit increases along this sequence. The maximal profit it obtains as high quality, in the limit, is $\pi_{2}^{l}=$ $a+b q_{1}-\lambda c q_{1}^{2}$. Hence,

$$
\pi_{2}^{f}-\pi_{2}^{l}=-a q_{1}+\frac{b^{2}\left(1-q_{1}\right)^{2}}{4 \lambda c}-b q_{1}+\lambda c q_{1}^{2} .
$$

At $q_{1}=b / c$ and $\lambda=1$, this reduces to $\pi_{2}^{f}-\pi_{2}^{l}=-a q_{1}+\left(\left(b^{2}(1-b / c)^{2}\right) / 4 c\right)>0$, where the last inequality follows since each of the three terms is strictly positive (recall that 
$a<0$ ). Therefore, Firm 2 prefers to offer low quality. Given $q_{1}=b / c$, its best response is $q_{2}=((b(1-b / c)) /(2 c))=(b / 2 c)-\left(b^{2} / 2 c^{2}\right)$, which is less than $b / c$.

\section{Lemma 1}

For convenience, we define $\pi_{2}^{f}-\pi_{2}^{l}$, from Equation (A1), as $g\left(q_{1}, \lambda\right)$. That is, $g\left(q_{1}\right.$, $\lambda)=-a q_{1}+\left(\left(b^{2}\left(1-q_{1}\right)^{2}\right) / 4 \lambda c\right)-b q_{1}+\lambda c q_{1}^{2}$. Now, $\hat{q}$ is the solution to $g\left(q_{1}, \lambda\right)=0$, so

$$
\hat{q}=\frac{b^{2}}{b^{2}+2 \lambda c(a+b)-2 \sqrt{\lambda c\left(b^{2}\right)(a+b)+a(a+2 b) \lambda c}} .
$$

We want to show that $\partial \hat{q} / \partial \lambda<0$. Taking the derivative with respect to $\lambda$ and simplifying this,

$$
\frac{\partial \hat{q}}{\partial \lambda}=-\frac{b^{2} c\left(2(a+b)+\frac{-b^{2}(1+b)-2 a(a+2 b) c \lambda}{\sqrt{c \lambda\left(b^{2}(a+b)+a(a+2 b) \lambda c\right)}}\right)}{b^{2}+2 \lambda c(a+b)-2 \sqrt{c \lambda\left(b^{2}(a+b)+a(a+2 b) \lambda c\right)^{2}}} .
$$

The denominator is obviously positive. If the numerator is positive as well, then clearly $\partial \hat{q} / \partial \lambda<0$ (note the negative sign). It is easy to see (taking the derivative of the numerator with $a$ ) that the numerator is decreasing in $a$. Therefore, since $a \leq 0$, if we show that the numerator is positive at $a=0$, then it must be so for all values of $a<0$. Substituting $a=0$ in the numerator leads to $b^{2} c(2 b-(b \sqrt{b}) / \sqrt{c \lambda})$. Since $(b / 2 c \lambda)<1$, the numerator is always positive. Therefore, $(\partial \hat{q} / \partial \lambda)<0$.

\section{Proposition 3}

Suppose the entrant offers high quality and sets $q_{2}>(b / 2 \lambda c)$ - that is, higher than its monopoly level. Since the best response of the entrant is above its monopoly level, it must set $q_{2}=q_{1}-\varepsilon$. Above $q_{2}{ }^{m}, \pi_{2}$ is declining in $q_{2}$, so any higher quality will lead to lower profit. However, for any $q_{2}$, the incumbent makes a higher profit by setting $q_{1}=$ $q_{2}+\varepsilon$ than by setting $q_{1}=q_{2}-\varepsilon$. The incumbent's profit at $q_{1}=q_{2}-\varepsilon$ is $\pi_{1}\left(q_{2}+\varepsilon\right)=$ $2\left(a+b\left(q_{2}+\varepsilon\right)\right)-c\left(q_{2}+\varepsilon\right)^{2}$, and its profit at $q_{0}=q_{1}=q_{2}-\varepsilon$ is $\pi_{1}\left(q_{2}-\varepsilon\right)=\left(2-q_{2}\right)(a+$ $\left.b\left(q_{2}-\varepsilon\right)\right)-c\left(q_{2}-\varepsilon\right)^{2}$.

Since $q_{2}>0$, in any equilibrium in which the entrant offers higher quality, for $\varepsilon$ close enough to zero, $\pi\left(q_{2}-\varepsilon\right)>\pi\left(q_{2}-\varepsilon\right)$. Since there is no equilibrium in which $q_{2}=q_{1}-\varepsilon$, the only other possibility is that the entrant is at its monopoly level, $q_{2}=$ $(b / 2 \lambda c)$.

Next, consider the best response of the incumbent, given that the entrant offers high quality and is choosing $q_{2}=(b / 2 \lambda c)$. The demand for Firm 1 in Period 1 when it is a follower is simply $\left(a+b q_{1}\right)\left(1-q_{2}\right)$. Adding the first-period demand of $a+b q_{1}$, and 
noting that $q_{2}=(b / 2 \lambda c)$, the profit of Firm 1 as low quality can be represented as $\pi_{1}^{f}=$ $\left(a+b q_{1}\right)(2-(b / 2 \lambda c))-c q_{1}{ }^{2}$. The first-order condition, $\left(d \pi_{1} / d q_{1}\right)=0$, directly yields the optimal value of $q_{1}$ to be $q_{1}=(b / c)-\left(b^{2} / 4 \lambda c^{2}\right)$.

Finally, we show that there exists a threshold for the cost advantage of the entrant, $0 \leq \lambda_{l} \leq 1$, such that for $\lambda<\lambda_{l}$, the entrant is the high-quality firm.

Suppose the incumbent offers high quality. Then, its optimal quality is $\tilde{q}=\max \left\{q_{1}{ }^{m}\right.$, $\hat{q}$ \}. Note that, since $\hat{q}$ is a function of $\lambda$, so is $\tilde{q}$. The profit of the incumbent when it offers high quality, therefore, is $\pi_{1}{ }^{l}(\lambda)=2(a+b \tilde{q})-c \tilde{q}^{2}$.

Suppose the incumbent offers low quality. Then, from Proposition 3 , the optimal quality of the entrant is $q_{2}=(b / 2 \lambda c)$. From this, we can calculate the incumbent's best response as $q_{1}=\left((b / c)-\left(b^{2} / 4 \lambda c^{2}\right)\right)$. Note that $q_{1}<q_{2}$ if and only if $\lambda<1 / 2+b / 4 c$. For such $\lambda$, the profit of the incumbent as low quality is computed to be $\pi_{1}^{f}(\lambda)=2 a-(a b /$ $2 \lambda c)+\left(b^{2} / 4 c\right)\left(2-(b / 2 \lambda c)^{2}\right)$.

Define the difference function, $h(\lambda)=\pi_{1}^{l}(\lambda)-\pi_{1}^{f}(\lambda)$, to be

$$
h(\lambda)=2 b \tilde{q}-c \tilde{q}^{2}+\frac{a b}{2 \lambda c}-\frac{b^{2}}{4 c}\left(2-\frac{b}{2 \lambda c}\right)^{2}
$$

Now, we need $\lambda>b / 2 c$ to ensure that $q_{2}{ }^{m}<1$. We have $\pi_{1}{ }^{f}(b / 2 c)=a+\left(b^{2} / 4 c\right)$, which is positive by Assumption 1, Part (ii). Consider $\pi_{1}^{l}(b / 2 c)$. At $\lambda=(b / 2 c), q_{2}{ }^{m}=1$. However, when $q=1$, the incumbent makes a loss, and the loss is even greater for $q>1$. Hence, $h(b / 2 c)<0$. Further, it is clear that $h\left(\lambda_{m}\right)>0$, since at $\lambda=\lambda_{m}$, the incumbent remains at its monopoly level when it is the leader.

Since $h(\cdot)$ is continuous, there exists at least one value of $\lambda \in\left((b / 2 c), \lambda_{m}\right)$ such that $h(\lambda)=0$. If there is only one such value, define this value to be $\lambda_{l}$. If there are multiple values, define the minimal value to be $\lambda_{l}$ and the statement of the proposition follows.

\section{Proposition 4}

Suppose engines choose to locate at the points that are optimal when there is no residual demand. Further, suppose engines choose optimal qualities given their locations, where the quality choice recognizes the presence of residual demand. We evaluate $d \pi_{1} / d x$ at these locations when there is residual demand. If this expression is negative, Engine 1 wishes to increase horizontal differentiation. If it is positive, Engine 1 would like to move closer to Engine 2. By symmetry, Engine 2 behaves in a similar manner.

Since, in case of no residual demand, optimal $q$ and $x$ are such that $q_{1} \leq(1-x)^{2}$, it is sufficient to consider only this case. We have

$$
\frac{d \pi_{1}}{d x}=\frac{\partial \pi_{1}}{\partial q_{1}} \frac{d q_{1}}{d x}+\frac{\partial D_{1}}{\partial q_{2}} \frac{d q_{2}}{d x}+\frac{\partial D_{1}}{\partial x} .
$$

The first term here is the effect of $x$ on $q_{1}$ and hence on subsequent profits. The second term is the indirect (strategic) effect of the change in Engine 2's quality when Engine 1 
changes its location. Finally, the third term is the direct (or demand) effect of moving on Engine 1's profit. Note that, by the Envelope Theorem, the first term is zero (i.e., the optimal $q_{1}$ is chosen by setting $\left.\left(\partial \pi_{1} / \partial q_{1}\right)=0\right)$. Therefore,

$$
\frac{d \pi_{1}}{d x}=\frac{\partial D_{1}}{\partial q_{2}} \frac{d q_{2}}{d x}+\frac{\partial D_{1}}{\partial x}
$$

In Equation (A2), determining $\partial q_{2} / \partial x$ requires an additional step, since we do not have the optimal $q_{2}{ }^{*}$ in closed form. We use implicit functions to find this derivative. Recall that the profit of each firm $i=1,2$ is $\pi_{i}=D_{i}-c q_{i}{ }^{2}$. Substitute in the value of $t$ from Equation (5) into $D_{1}, D_{2}$. The first-order conditions for optimal quality choice are

$$
\begin{gathered}
\frac{\partial \pi_{1}}{\partial q_{1}}=\frac{1-q_{2}}{2 \sqrt{q_{1}}}+\frac{q_{2}}{2(1-x-y)}-2 c q_{1}=0 \\
\frac{\partial \pi_{2}}{\partial q_{2}}=\frac{1-q_{1}}{2 \sqrt{q_{2}}}+\frac{q_{1}}{2(1-x-y)}-2 c q_{2}=0 .
\end{gathered}
$$

Now, to find $\partial q_{2} / \partial x$, we implicitly differentiate Equations (A3) and (A4). This gives

$$
\begin{gathered}
-\left(2 c+\frac{1-q_{2}}{4 q_{1}^{3 / 2}}\right) d q_{1}+\left(\frac{1}{2(1-x-y)}-\frac{1}{2 \sqrt{q_{1}}}\right) d q_{2}+\left(\frac{q_{2}}{2(1-x-y)^{2}}\right) d x=0 \\
\left(\frac{1}{2(1-x-y)}-\frac{1}{2 \sqrt{q_{2}}}\right) d q_{1}-\left(2 c+\frac{1-q_{1}}{4 q_{2}^{3 / 2}}\right) d q_{2}+\left(\frac{q_{1}}{2(1-x-y)}\right) d x=0 .
\end{gathered}
$$

In the symmetric equilibrium, $q_{1}=q_{2}$. Further, the optimal locations without residual demand are $x=y=(1 / 2)-\left(1 /\left(22^{2 / 3} c^{1 / 3}\right)\right)$. Substituting these values and solving yields

$$
\frac{d q_{2}}{d x}=\frac{42^{2 / 3} c^{2 / 3} q_{2}^{5 / 2}}{2^{1 / 3}+2^{1 / 3} q_{2}+q_{2}^{3 / 2}\left(-4 c^{1 / 3}+82^{1 / 3} c\right)} .
$$

For these values of $x$ and $y$, we can further find the optimal qualities. We obtain $q_{1}=$ $q_{2}=\left(1 /\left(22^{1 / 3} c^{2 / 3}\right)\right)$. Substituting $q_{2}$ in Equation (A5) yields

$$
\frac{d q_{2}}{d x}=\frac{1}{\frac{-c^{1 / 3}}{2^{1 / 3}}+6 c}=\frac{2^{1 / 3}}{62^{1 / 3} c-c^{1 / 3}} .
$$

Now, $\left(\partial D_{1} / \partial q_{2}\right)=(1 / 2)\left(1-x-y-2 \sqrt{q_{2}}-\left(q_{2} /(1-x-y)\right)\right)$. Substituting for $q_{2}, x$, and $y$ leads to $\left(\partial D_{1} / \partial q_{2}\right)=-\left(1 /\left(2^{2 / 3} c^{1 / 3}\right)\right)$. Similarly, $\left(\partial D_{1} / \partial x\right)=1-\left(q_{2} / 2\right)$, which simplifies 
to $1-\left(1 /\left(42^{1 / 3} c^{2 / 3}\right)\right)$. Substituting these three derivatives into Equation (A2) and simplifying now gives

$$
\frac{d \pi_{1}}{d x}=1-\frac{1}{62^{2 / 3} c^{4 / 3}-2^{1 / 3} c^{2 / 3}}-\frac{1}{42^{1 / 3} c^{2 / 3}} .
$$

Evaluating this expression numerically, we find it is negative for $c=0.25$ and positive for $c=1$, and increasing in $c$. Hence, there exists a $\hat{c} \in(0.25,1)$ such that, if $c>$ $\hat{c}$, then $\left(d \pi_{1} / d x\right)>0$. Thus, firms wish to locate closer to each other than when there is no residual demand. For $c<\hat{c}$, we have $\left(d \pi_{1} / d x\right)>0$, so that firms wish to be further apart than when there is no residual demand. 